\title{
Penetrating Anterior Neck Injury: A Multidisciplinary Approach
}

\author{
Adebola S.O ${ }^{1}$, Ologe F.E ${ }^{2}$, ${ }^{*}$ Ogunkeyede S.A ${ }^{1}$, Adedayo G.A ${ }^{1}$, \\ Ogundoyin O.A ${ }^{1}$. \\ ${ }^{I}$ Department of Otorhinolaryngology, Ladoke Akintola University of Technology Teaching Hospital, Ogbomoso, \\ Nigeria \\ ${ }^{2}$ Department of Otorhinolaryngology; University of Ilorin Teaching Hospital, \& College of Health Sciences, \\ University of Ilorin, Ilorin,, Nigeria.
}

\begin{abstract}
s:
Introduction: Penetrating laryngeal injuries are rare, and they are frequently associated with pharyngeal, vascular and spinal injuries. Its management is multi-disciplinary and challenging.

Case presentations: We hereby report a case of cut throat injury with complete transection of laryngeal thyroid cartilage and its management.

Conclusion: The purpose of this report is to accentuate that cut throat injuries in our environment occurs but it is rare. The effective and good management outcome of the patient requires effective teamwork of Otorhinolaryngologist, anesthesiologist, nurses, dietitian, social-workers and clinical psychologist. Laryngeal injury can be repair without post-operative restricting of neck movement for ensure tension free anastomosis in the wound.
\end{abstract}

Key Words: Cut Throat, Thyroid cartilage Transection, Laryngeal injury, multi-disciplinary

\section{Introduction}

The anterior neck injuries are accidental, suicidal or homicidal in nature. The individual with penetrating anterior neck injury (cut throat injury) presents with airway compromise, aspiration or acute blood loss with hypoxemia because of the airway injury and the injury to major vessels in the neck.

Timely management of the wounded airway is essential in penetrating anterior neck injury, by instituting an airway using endotracheal intubation or through tracheostomy, this is done prior to the neck wound exploration and repair of the transected tissues.' Laryngeal injury is life threatening with a potential long-term morbidity: Laryngeal stenosis and pharyngo-cutaneous fistula may complicate the surgical repair. ${ }^{2}$, Penetrating anterior neck injuries requires interdisciplinary treatment; the anesthetist, nurses, speech therapist and clinical-psychologist working as a team with the Otolaryngologist are needed for the good and effective patient's care.

This paper reviews the management of a man with cut throat from a homicidal attack who presented to our hospital within a period of 11 hours after the cut throat injury.

\section{Case Summary}

A 24year old male Fulani cattle farmer was admitted to department of Otorhinolaryngology Ladoke Akintola University of Technology Teaching Hospital, Ogbomoso, via accident and emergency department with assassination attack on him by assailant who slashed his throat with knife after tying his hand to the back and blind folded him with an intent to rob him of the money he got from the sales of some of his cows. The police found him in a pool of blood with a slashed throat, about ten hours after the injury and was transported to hospital in police pick-up van. No resuscitation was received prior hospital presentation.

Examination findings on arrival at the hospital revealed a pale, middle aged man, who was dyspnoiec with inspiratory stridor and was in shock with feeble, rapid pulse of 130 beats/min and a blood pressure of $70 / 45 \mathrm{mmHg}$. There was bilateral basal crepitation's with reduce air entering, which was worse on the right basal lung zone, though there was no gross abnormality on the chest x-ray. Air bubbles-out from the anterior neck wound, at the level of thyroid cartilage and the medial aspects of both sternocleidomastoid muscles were transected (Fig. I). This laceration was about $12 \mathrm{~cm}$ in length, exposing the larynx and hypopharynx with minimal bleeding. He also had bruises on his face and upper limbs. Immediate resuscitation was commenced, he was intubated with a cuffed endotracheal tube, through the exposed laryngeal inlet in the anterior neck wound to secure airway (Fig. II). The cuff of the endotracheal tube was inflated to prevent seepage of the blood into the lower airway and for effective ventilation by the anaesthestist. He had two units of fresh whole blood transfused, tetanus prophylaxis, analgesics, and parenteral antibiotics were given. He then had definitive treatment which involved an emergency neck exploration under general anaesthesia. Findings at surgery were that of; carotid arteries and internal jugular veins were missed narrowly, larynx and hypopharynx were injured, and there was 
no disruption of anterior commissure tendon. He had tracheostomy, wound debridement and the wound edges were closed with the aim of restoration of breathing, swallowing and phonation (hypopharyngngoplasty + laryngeal repair). Nasogastric tube was passed intra operatively to serve as a stent and for the feeding of the patient post operatively.

While the transected hypopharynx was repaired in two layers using vicryl $4 / 0$ meticulously: inverting the mucosa and closing the second sub-mucosal layer, in a continuous fashion. The muscle layer was loosely 'tacked' over the repaired larynx using vicryl $2 / 0$ suture interruptedly. The transected thyroid cartilage was sutured circumferentially with $4 / 0$ prolene sutures placed interruptedly at an interval of 5-6 mm. The sutures were taken through muco-perichondrium posteriorly but it was perichondrium to perichondrium externally (Figs. III a \& b).

Chest physiotherapy was commenced within 24hours after the surgery for 5-days with remarkable improvement in chest auscultation. He was commenced on fortified high caloric and protein diet via Nasogastric tube (NGT) feeding after 48 hours (Fig V) by the dietitian. A dye test carried out on the 10th day post-surgery, with diluted methylene blue gave no evidence of a pharyngo-cutaneous fistula. Thereafter he was commenced on peri-NGT graded oral diet, and the NGT was removed 2 days later when he was able to swallow the premorbid normal adults' diets without difficulty.

The neck was not flexed post-operatively because there was no tension anastomosis in the wound at surgery also, the injury to neck muscles were minimal, and these muscles will prevent tension in the wound. The anterior neck wound sutures were removed on the 7th post-operative day, with satisfactory wound healing and he was completely decanulated on 21 st day. There was a mild-change in his pre-morbid voice which gradually resolved after few sessions of voice therapy. He was discharged home on the 29th day post injury with good quality of voice, no difficulty with breathing, or swallowing and there was no evidence of psychiatry illness or nutritional derangements. He was psycho-social rehabilitated by the clinical-psychologist before the hospital discharge and the social-worker rehabilitated him back to his family and his workplace

\section{Discussion}

Laryngeal injury is relatively uncommon injury estimated at approximately 1 in every 22,900 emergency room visits, and penetrating neck injuries accounts for $5-10 \%$ of all trauma cases. There is risk of damage to important and vital structures in the neck (larynx, pharynx, trachea, oesophagus and the great vessels) if there is a cut- throat injury. An organized and appropriate management procedure results in increased patient survival as well as improved long term functional outcomes.

Patients' resuscitation should be commenced at the scene of accident or the injury and this should be continued until patients arrive in the hospital. The airway should be secured or patient should be positioned in such a way to prevent further aspiration of blood and secretion into the lower air-way, and the haemorrhage from the wound should be controlled. In resource challenge environment like this the ambulance is not available to transport the patient to the hospital and there were few or no trained paramedics to assist the victims at initial resuscitation before getting to hospital. This patient was brought to the hospital after about 11 hour post injury in a police-van and not by ambulance, without any resuscitation prior to hospital admission. He lost significant blood from the wound and the blood also soiled the lower air-way. This might be responsible for the clinical findings on the basal lung zones on admission, though the radiologist reported the chest X-ray as normal. There is a need for improvement on police surveillances in other to prevent or detect crime and to rescue the affected victims on time in Nigeria.

The air-way was protected by cuffed endotracheal tube by the anaesthetist. Schaefer et al stated that intubation following laryngeal or tracheal trauma is hazardous, but the American College of Surgeons recommends an attempt at intubation, though tracheostomy is to be performed in failed intubation. Tracheostomy is preferred to intubation, this avoid additional injury to larynx in an unstable airway. The fibreoptic laryngoscope can be used to intubate in a cut throat injury, this has reduced the need for tracheostomy and its attendant complications.

The hospital administrator gave consent for the surgical procedure, because the patient was unstable to give consent and no relation was around at time of surgery.

The examination of the patients ought to be directed to determine the extent of the cut- throat injuries and other accompanying injuries in the patients. Management should be instituted in good time to prevent affordable complication(s). The most common associated injuries are head injuries, cervical spine fractures, and esophageal injuries. Cut throat injury complications may be chronic airway obstruction, wound infection, scar, persistent voice changes and dysphagia, permanent tracheostomy due to laryngeal stenosis.

Leakage of air as evident by bubbling of air through the neck wound in this patient indicates perforation of larynx or trachea. The use of non-absorbable suture (prolene 4/0) in the anastomosis of transected thyroid cartilage (larynx) in this patient was to provide strength and tension free anastomosis, stainless steel can also be used to provide strength and tension free anastomosis. The tension free anastomosis can also be achieved 
by restricting the head movement by use of cervical neck collar or by suturing the chin to the sternum ${ }^{16}$, in our patient the neck movement was not restricted. Hemostasis was secured at surgery, and all the devitalized tissues were debrided after copious irrigation of the wound with Hartman's solution at surgery, these will reduce the wound contaminants and the microbial colonization of the wound. The neck wound drain was not used after the wound repair; Bassam et al have shown that Neck surgery is safe without a drain. The parenteral broad spectrum antibiotic was given preoperatively and was continued post-operatively to prevent microbial colonization and multiplication in the wound. This might have prevented neck wound infection and abscess formation in the neck. This patient had his operative management within 2 hours of presentation, this is important in good management outcome, , , unlike if it is delayed for wound oedema to resolve. Krug et al recommended that pharyngeal, hypopharyngeal and laryngeal mucosal lacerations should be repaired within 24 hours, because delay in repair of laryngeal mucosa lacerations has an effect on airway stenosis and voice.

The psychiatrist review of the patient confirmed that there was no behavioral abnormality that could have led to deliberate self- harm or the development of psychiatric illness after the attack. Iseh et al observed that the majority of cut throat injuries were due to suicide attempt in people with psychiatric illness. The change in voice in this patient might be due to laryngeal oedema, which resolved with time.

The medical social workers of the hospital provides the initial funds for the patients care before the patient was stable enough to give the details and the contact of his relations, who were later traced by the social workers in-conjunction with the Nigerian police. The patient had challenges in paying the hospital bill, the cost of the hospital stay and the procedure was one hundred and twenty thousand naira (750 USD). In developing country with poor resources and ineffective health insurance schemes, the patient care is hampered by financial challenge.

\section{Conclusion:}

Cut throat injuries happen in our environment, though rear. The air way must be secured before wound exploration and wound repair. Tension free anastomosis is essential at wound repair. A team work of the Otolaryngologist, Anesthetist, Social workers, Dietitians (Nutritionist), Psychiatrist and Clinical-psychologist are needed for the patients' management and good outcome. Laryngeal injury can be repair without postoperative restricting of neck movement to ensure tension free anastomosis in the wound.

Fig. I: Showing hypopharyngeal injury, injury to sternocledomastoid muscles, the cut edges of thyroid cartilage, the vocal cords and laryngeal inlet

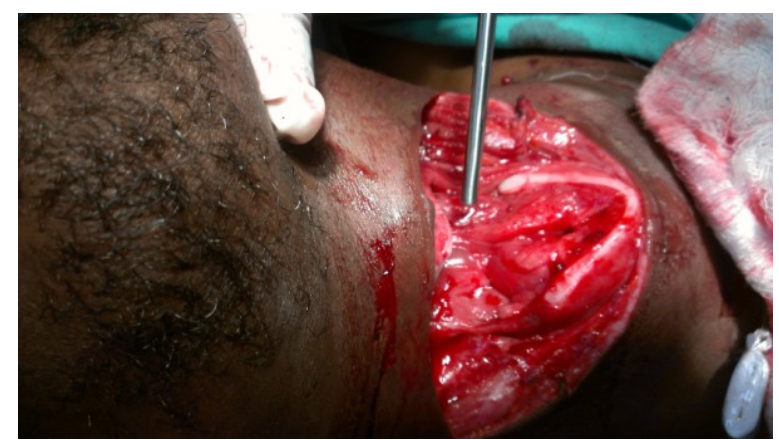

Fig. II: Showing the laryngeal intubation with endotracheal tube through the anterior neck wound

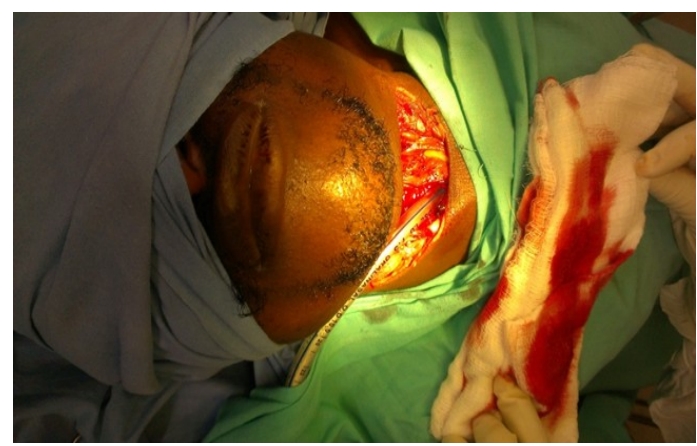

Figs III a and b: Showing the repair of larygeal thyroid cartilage with interupted non- absorbable suture,nasogastric tube inleft nasal cavity and anesthesia is been delivered viathe tracheostomy 
Fig.III a

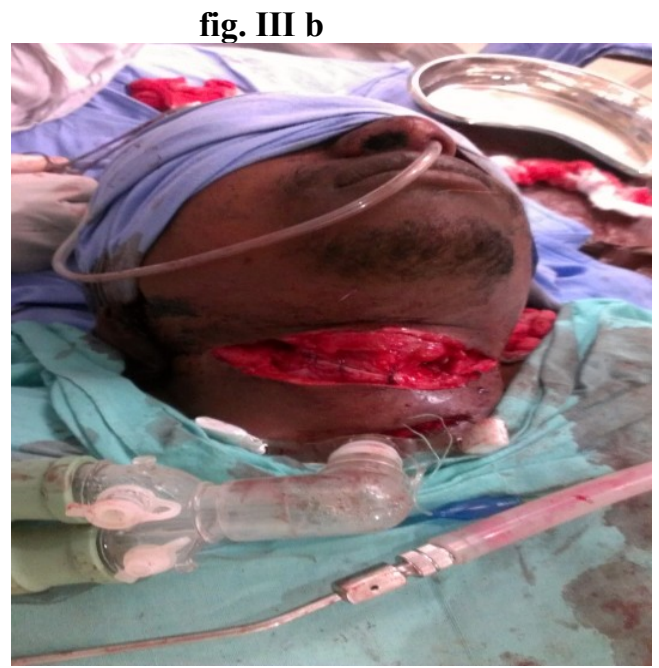

Fig. IV: Showing the the skin closure of the wound and the tracheostomy wound at surgery.

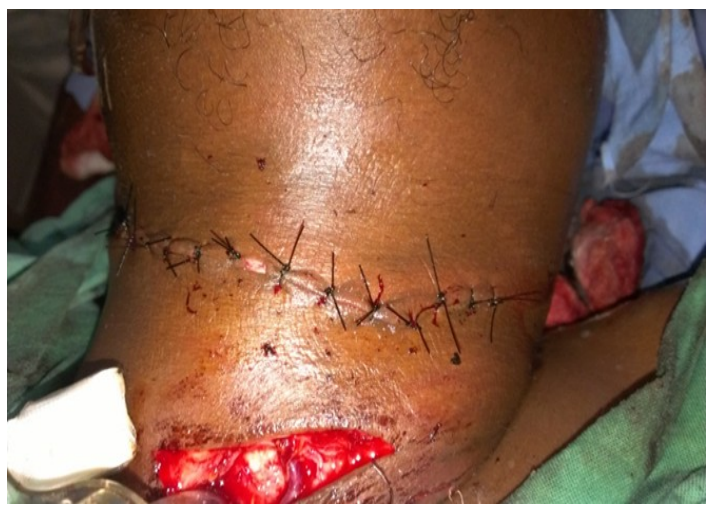

Fig. V: The anterior wound is well apossed, nasogastiric tube in place annd the cuffed tracheostomy tube in place on the 3rd post operative day.

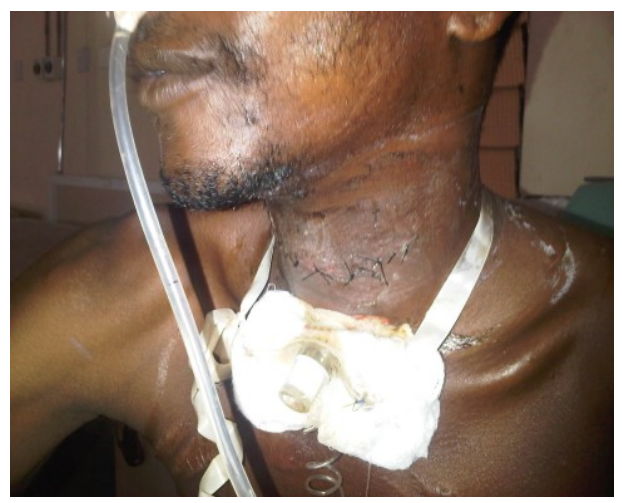

\section{References}

[1]. Shreyas S.J, Mohan J, Sunil N, Sunita B, Saurabh A, Neha P. Technicality of Managing Cut Throat Injury. International Journal of Otolaryngology and Head \& Neck Surgery, 2013; 2: 11-12.

[2]. Ezeanolue B: Management of the upper airway in severe cut throat injuries. Afr J Med Med Sci 2001, 30(3):233-235.

[3]. Venkatachalam SG, Palaniswamy Selvaraj DA, Rangarajan M, Mani K, Palanivelu C: An unusual case of penetrating tracheal ("cut throat") injury due to chain snatching: the ideal airway management. Indian J Crit Care Med 2007, 11(3):151-4.

[4]. Schaefer SD. Management of acute blunt and penetrating external laryngeal trauma. Laryngoscope. 2014; 124(1):233-44.

[5]. Sett S, Isser DK. Laryngotracheal stenosis and pharyngocutaneous fistula in cut throat injuries: how we manage them. Indian J Otolaryngol Head Neck Surg. 2000; 52(3): 315-318.

[6]. Herzog M, Hoppe F, Baier G, Dieler R. Injuries of the head and neck in suicidal intention. Laryngorhinootologie 2005, 84(3):17681

[7]. Kandogan T, Olgun L, Gültekin G, Aydar L, Mercan B, Ozuer ZM. External laryngeal trauma.Swiss Med Wkly 2003;133:372.

[8]. Rajesh Kumar Kundu1 Bivas Adhikary, Sukanya Naskar. "A clinical study of management and outcome of 60 cut throat injuries". Journal of Evolution of Medical and Dental Sciences 2013; 2(49):9444-9452.

[9]. Schaefer SD, Close LG. Acute management of laryngeal trauma. Ann Otol Rhinol Laryngol 1989;98: 98-104 
[10]. American college of surgeons committee on trauma .Airway and ventilatory management.In: Advanced trauma life support for doctors.6th ed.Chicago:1997; pp 64

[11]. Shabbir Akhtar, Sohail Awan Laryngotracheal trauma: its management and sequelae JPMA 2008;58:241

[12]. Venkatachalam SG, Palaniswamy Selvaraj DA, Rangarajan M, Mani K, Palanivelu C: An unusual case of penetrating tracheal ("cut throat") injury due to chain snatching: the ideal airway management. Indian J Crit Care Med 2007, 11(3): 151-4.

[13]. Jewett BS, Shockley WW, Rutledge R. External laryngeal trauma analysis of 392 patients. Arch Otolaryngol Head Neck Surg 1999; 125: $877-80$

[14]. Kurien M, Zachariah N. External laryngotracheal trauma in children. Int J Pediatr Otorhinolaryngol 1999;49: 115-9.

[15]. Minard G, Kudsk KA, Croce MA, Butts JA, Cicala RS, Fabian TC. Laryngotracheal trauma. Am Surg 1992; 58:181-7.

[16]. Bryce DP. "The Surgical Management Laryngotracheal Injury," The Journal of Laryngology \& Otology, 1972; 86 (6): 547-587.

[17]. Bassam A, Ghsan S, Habib R, Gerard A, Claude G. Safety of Thyroidectomy and Cervical Neck Dissection without Drains. Can J Surg 2012; 55(3):199-203

[18]. Butler AP,Wood BP, O'Rourke AK, Porubsky ES. Acute external laryngeal trauma: experience with 112 patients.Ann Otol Rhinol Laryngol $2005 ; 114: 361-8$.

[19]. Hwang SY,Yeak SC.Management dilemmas in laryngeal trauma. J Laryngol Otol 2004; 118: $325-8$

[20]. Rabbani MZ,Rashid D, Majeed A. Blunt, External laryngeal trauma,clinical analysis \& management,experience at Combined Military Hospital,Rawalpindi.Pakistan J Otolaryngol 2002; 18: 23-5

[21]. Olson NR,Miles WK. Treatment of acute blunt laryngeal injuries. Ann Otol Rhinol Laryngol 1971; 80:704-9.

[22]. Krug EG, Sharma GK, Lozano R. The global burden of injuries, American Journal of Public Health 2000; 90 : 523-6

[23]. Iseh KR, Obembe A. Anterior neck injuries presenting as cut throat emergencies in a tertiary health institution in north western Nigeria. Niger J Med 2011;20(4):475-8 